\title{
EVALUATING THE CONSISTENCY OF REMOTE SENSING BASED SNOW DEPTH PRODUCTS IN ARID ZONE OF WESTERN CHINA
}

\author{
Qiming Zhou \& Bo Sun* \\ *corresponding author, E-mail: sun.bo@msn.com
}

Department of Geography, Hong Kong Baptist University, Kowloon Tong, Kowloon, Hong Kong, S.A.R., China

KEY WORDS: Snow ice, depth, global-environmental-databases, evaluation, data reliability, western China

\begin{abstract}
:
Snow cover is a sensitive indicator of global climate change. Among various snow cover parameters, snow depth which can indicate snow accumulation is essential for retrieving snow water equivalent. In arid zone of western China, based on different inversion models, snow depth products retrieved from passive microwave remote sensing sensors have been issued. However, none of them can promise a high accuracy due to the spatial heterogeneity of snow cover especially in mountain areas with complex terrain. This study aims to analyse the reliability of existing long-term snow depth products in arid zone of western China. Two datasets are compared including GlobSnow snow water equivalent (SWE) product and snow depth dataset provided by Environmental and Ecological Science Data Center for West China. Statistical techniques like regression and intra-class correlation coefficient (ICC) models are employed to examine the consistency of these two remote sensing based snow depth products in a selected sampling site. More than 260 samples during three years are tested covering from snow falling to snow melting periods. Result shows that there is a discrepancy between the two datasets. Accordingly, remote sensing based snow depth measurement is not reliable in mountain areas in arid zone of western China. This study gives an awareness of the stabilities of current snow depth detection models. A further study is expected to calibrate snow depth products based on in-situ observation and measurements from ground monitoring stations.
\end{abstract}

\section{INTRODUCTION}

Snow cover in mountain areas is increasingly considered as one of the most sensitive indicators of global climate change due to the less direct influence of human activities. Under the background of global warming, the long-term trend of snow cover change has been focused.

Among snow cover change studies, snow depth which indicates snow accumulation is an essential parameter for retrieving the amount of water contained within the snowpack (snow water equivalent). Passive microwave remote sensing data has shown the capability of providing a large-extent and successive dataset for long-term snow cover change studies in terms of snow depth information. The retrieval of snow depth from passive microwave data is on the basis of scattering theory. Retrieval algorithms are based on the difference in emissivity between two microwave frequencies, e.g., 18/19 and 36/37 GHz (Chang et al., 1987). Historical passive microwave remote sensing data can date back to 1978. Commonly used sensors and platforms include SMMR carried by Nimbus-7, SSM/I carried by DMSP satellite series and AMSR-E carried by EOS satellite. Based on the same data source, various snow depth retrieval algorithms have been developed and several snow products have been released.

At present, although long-term snow depth and snow water equivalent products at global scale have been issued, none of them can promise a high accuracy for everywhere in the world. One of the major reasons is that physical parameters of snow cover can be different at different places. Besides, as a known issue, the error caused by spatial heterogeneity is hard to be solved. Data accuracy might become lower in mountain areas and in the place where underlying surface of snow cover is complex.
In this study, two existing snow products are collected. Depth information is retrieved from the same long-term passive microwave remote sensing dataset. We attempt to evaluate the consistency of snow depth measurements from these two products and assess the reliability of the products for mountain areas in arid zone of western China.

\section{METHODOLOGY}

Pairs of snow depth measurements sampled from two snow datasets are compared for examining their differences by using statistical techniques. Given that the data is at ratio scale in terms of the level of measurement, regression and intra-class correlation coefficient (ICC) models are employed to test the consistency of the two datasets.

\subsection{Existing snow depth products}

Two existing snow depth products are tested in this study including Long-term Snow Depth Dataset of China and GlobSnow SWE product.

Long-term Snow Depth Dataset of China is issued by Environmental and Ecological Science Data Center for West China (EESDCWestChina). Snow depth retrieval algorithm is based on a modified Chang's algorithm so that the algorithm can be suitable for snow depth retrieval in China (Che, et al., 2008). For the accuracy of snow depth, it is reported that the standard deviations can reach to $60 \mathrm{~mm}$ regarding different passive microwave sensors (Che, et al., 2008).

GlobSnow SWE product is issued by Finish Meteorological Institute, which is supported by a European Space Agency (ESA) project. Snow depth retrieval algorithm is based on a semi-empirical snow emission model (called HUT model) (Pulliainen, 2006). 


\subsection{Sample site and applied data}

The sample site is selected at the place where Tianshan Station for Snowcover \& Avalanche Research sits. It is located at the western section of Tianshan Mountains at $43^{\circ} 16^{\top} \mathrm{N}$ and $84^{\circ} 24^{\circ} \mathrm{E}$ and at an altitude of 1,776 meters above sea level. Annual average precipitation for this area is $830.2 \mathrm{~mm}$ (XIEG, 2012).

Snow depth information in the first quarter of a year is focused on so as to cover the period from snow falling to snow melting. Data from 2008 to 2010 are collected. Apart from some missing data, 265 samples (days) are involved in the following analysis.

\subsection{Data preprocessing}

As for long-term snow depth dataset of China, daily snow depth information can be directly extracted. While GlobSnow SWE product only provides snow water equivalent rather than snow depth information. A conversion algorithm between these two parameters should be adopted to make the two datasets comparable. The following formula can be used to determine snow water equivalent from snow depth and density:

$$
S W E=S D \cdot \rho_{\text {snow }} / \rho_{\text {water }}
$$

Where

$$
\begin{aligned}
& \text { SWE = snow water equivalent; } \\
& \text { SD = snow depth; } \\
& \rho_{\text {snow }}=\text { snow density; } \\
& \rho_{\text {water }}=\text { water density. }
\end{aligned}
$$

Since snow density might be different at different places, conversion of snow depth to snow water equivalent will bring data uncertainty. Thus, we convert snow water equivalent to snow depth in our experiment, according to the assumption of a constant snow density of $0.23 \mathrm{~g} / \mathrm{cm}^{3}$ for Eurasia in the retrieval algorithm of GlobSnow SWE product (Pulliainen, 2006).

\subsection{Examination of data consistency}

2.4.1 Regression model: Scatter plot is usually adopted to visualize the relationship between two variables. Dots in scatter plot should be concentrated on the line of $y=x$ if two variables measure the same value. For this study, suppose snow depth measurements from two different methods are nearly the same, a simple linear regression can be used to express their relationship:

$$
Y=b X
$$

Where

$$
\begin{aligned}
& Y=\text { one measurement by method A; } \\
& X=\text { another measurement by method } \mathrm{B} ; \\
& b=\text { the slope of regression line. }
\end{aligned}
$$

In this regression model, snow depth from long-term snow depth dataset of China is set as independent variable $(X)$; and snow depth retrieved from GlobSnow SWE product is set as dependent variable $(Y)$. The intercept of regression line is supposed to be zero when snow depth from long-term snow depth dataset of China shows a zero value. Therefore, the constant in linear regression model is not included.

If two datasets have a good consistency, the slope of $b$ should be close to 1. Larger than 1 means the estimation of GlobSnow SWE product tends to be larger than that of long-term snow depth dataset of China, and vice versa.
2.4.2 Intra-class Correlation Coefficient: Intra-class correlation coefficient (ICC) is commonly used in psychological studies to measure the reliability of measurements from two or more judges (McGraw \& Wong, 1996). It reflects the extent to which ratings of the same group given by different judges tend to be alike. People tried to use it for answering the question whether two methods can be used interchangeably (Bland \& Altman, 1990). In this study, this index is used for evaluating the consistency of snow depth measurements from two different snow depth retrieval methods.

When using ICC to measure the agreement of ratings, one should choose an appropriate ICC model through making three decisions: (1) which variance model should be adopted: oneway, two-way random or two-way fixed; (2) are you interested in absolute agreement or just the consistent ratings without the same actual scores? (3) whether you plan to rely on a single judge or a combination of several judges? (Shrout \& Fleiss, 1979; Norušis, 2012). As for this study, two-way random model with ICC type of absolute agreement is chosen. Average measurement for multiple judges is employed. The value of ICC should be between 0 and 1. The larger the ICC value is, the better the data consistency shows.

\section{RESULTS AND ANALYSIS}

Figure 1 gives an overall perspective of the consistency of snow depth measurements from different snow products. Although a big part of samples show a good data consistency which are concentrated on or crossed by the reference line $y=x$, many dots are still far away from the line. Dots near the bottom (the horizontal axis) mean that some samples detected with snow cover in EESDCWestChina product are reported as snow-free samples in GlobSnow product. Besides, according to the slope of regression line in Table 1, 0.76 is not close to 1 , which means these two datasets do not correlate well.

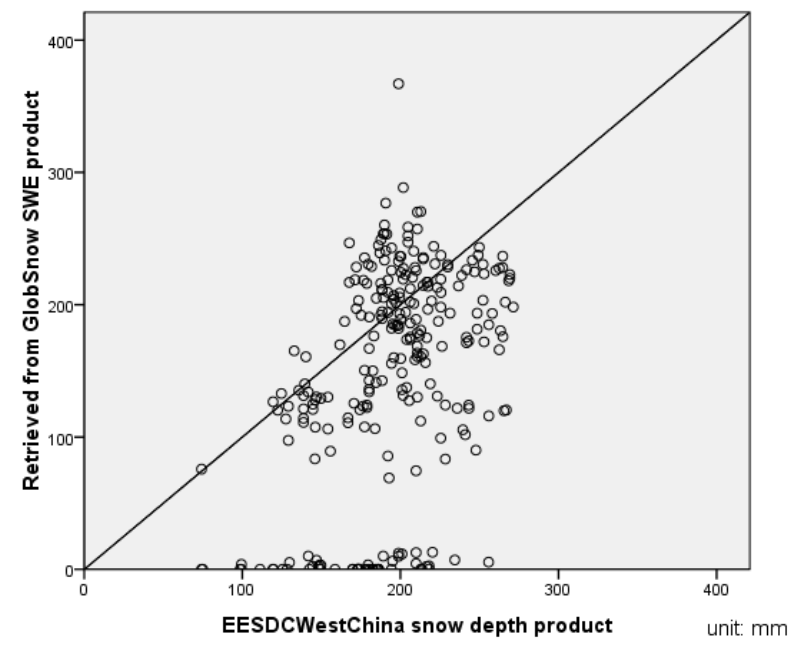

Figure 1. Scatter plot of EESDCWestChina snow depth measurement against snow depth retrieved from GlobSnow SWE product at sample site for the first quarter of the year of 2008 to 2010

When examining data consistency by different years, results show that snow depth measurement has a low level consistency in 2008 with the slope of 0.63 and a higher level consistency in 2010 with the slope of 0.93 separately (see Table 1). 
Those facts can be corroborated by ICC index. From Table 2, there are some variations of ICC scores among different sample periods. ICC of 2010 is larger than that of the other sample periods. Although this, low score in general $(0.485)$ means that snow depth measurements are not in agreement as for the whole sample space.

\begin{tabular}{|c|c|c|c|}
\hline Test period & Slope $(b)$ & R square & Sig. level \\
\hline $2008-2010$ & 0.76 & 0.79 & 0.05 \\
\hline 2008 & 0.63 & 0.78 & 0.05 \\
\hline 2009 & 0.81 & 0.79 & 0.05 \\
\hline 2010 & 0.93 & 0.87 & 0.05 \\
\hline
\end{tabular}

Table 1. Regression results based on pairs of snow depth measurements from two datasets from January to March at different periods

\begin{tabular}{|c|c|}
\hline Test period & ICC score \\
\hline $2008-2010$ & 0.485 \\
\hline 2008 & 0.575 \\
\hline 2009 & 0.383 \\
\hline 2010 & 0.668 \\
\hline
\end{tabular}

Table 2. ICC scores in terms of average measures at different periods

The impact of snow melting on the stability of snow depth detection is analyzed. To contrast snow depth measurements in January to March, result shows a better consistency in January than March (Figure 2). The regression results shown in Table 3 can also indicate the same conclusion. Data from the two products sampled in January has a high correlation.

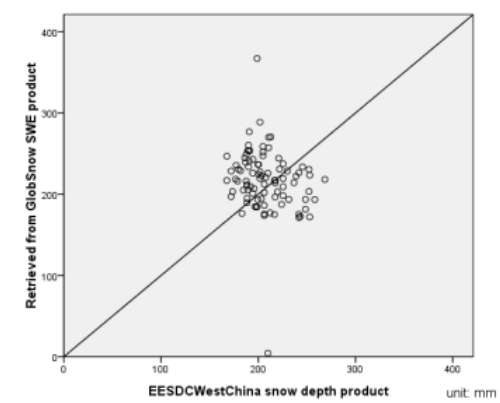

(a) January

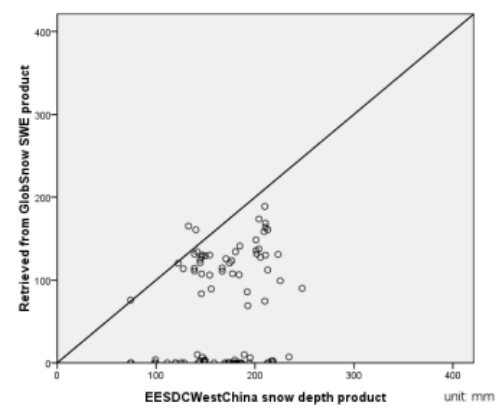

(b) March

Figure 2. Scatter plot of EESDCWestChina snow depth measurement against snow depth retrieved from
GlobSnow SWE product for snow falling (figure (a)) and snow melting (figure (b)) periods

\begin{tabular}{|c|c|c|c|}
\hline Test period & Slope $(b)$ & R square & Sig. level \\
\hline January & 1.03 & 0.95 & 0.05 \\
\hline March & 0.38 & 0.52 & 0.05 \\
\hline
\end{tabular}

Table 3. Regression results based on the data in snow falling period (January) and snow melting period (March)

\section{DISCUSSION}

Statistical techniques provide a quantitative means to assess the reliability of remote sensing based snow depth products. Scatter plot and simple linear regression model can give a general description of data consistency. However, the conclusion could be unreliable in some cases. Consider a case that samples are evenly dispersed in the upper and lower parts of the line $y=x$, the slope of regression line based on those samples can highly approach to 1 . However, this kind of dataset does not fit the requirement of data consistency.

ICC index gives another way to measure the consistency of two datasets. It is conceptualized as the ratio of between groups variance to the total variance (Shrout \& Fleiss, 1979). Something should be pointed out that ICC also has its limitation. This kind of coefficient depends on the range of observed values. For example, as for this study, ICC is not suitable for evaluating the consistency of snow depth measurements in January because the values in January are homogeneous.

In this study, snow depth measurement from two snow products didn't show a good consistency. The reasons may come from the following aspects:

1. The inaccuracy originated from snow depth retrieval algorithm;

2. The spatial resolution of snow depth products is too coarse (around 25km). In mountain areas, spatial heterogeneity within a pixel will cause measurement uncertainty in snow depth detection methods;

3. Snow depth retrieval algorithms are normally based on dry snow. The quality of snow depth products during snow melting periods will become instable and terrible.

\section{CONCLUSION}

This study has tested the reliability of two remote sensing based snow depth products in mountain areas of arid zone of western China. Statistical techniques include regression and intra-class correlation coefficient methods are employed to examine the consistency of snow depth measurements.

Results show that snow depth measurements from the two selected products do not correlate well. The difference between them can be very large especially in snow melting period. Because of the low consistency, it is hard to say that snow depth measurement based on passive microwave remote sensing is reliable for mountain areas. Although challenges still exist when retrieving snow depth from passive microwave data with a high accuracy, effort should be undertaken to make the remote sensing based snow data more reliable. In the future, in-situ observation data from ground monitoring station is expected to be collected for accuracy assessment and calibration of existing snow depth products. 


\section{ACKNOWLEDGEMENTS}

This research is supported by the Hong Kong Baptist University Faculty Research Grant (FRG2/11-12/030). Long-term snow depth dataset of China is provided by Environmental \& Ecological Science Data Center for West China, National Natural Science Foundation of China (http://westdc.westgis.ac.cn). GlobSnow SWE product is provided by Finish Meteorological Institute.

\section{REFERENCES}

Chang, A.T.C., Foster, J.L., \& Hall, D.K., 1987. Nimbus-7 SMMR derived global snow cover parameters, Annals of Glaciology, (9), pp. 39-44.

Xinjiang Institute of Ecology and Geography (XIEG), 2012. "Tianshan Station for Snowcover \& Avalanche Research, XIEG, CAS", Retrieved from XIEG website: http://english.egi.cas.cn/rs/sr/tsar/201203/t20120326_82839.ht $\mathrm{ml}$ (12 April, 2012).

Pulliainen, J., 2006. Mapping of snow water equivalent and snow depth in boreal and sub-arctic zones by assimilating space-borne microwave radiometer data and ground-based observations, Remote Sensing of Environment, 101, pp. 257-269.

McGraw, K.O., \& Wong, S.P., 1996. Forming inferences about some intraclass correlations coefficients. Psychological Methods, 1(1), pp. 30-46.

Bland, J.M., \& Altman, D.G., 1990. A note on the use of the intraclass correlation coefficient in the evaluation of agreement between two methods of measurement, Computers in Biology and Medicine, 20 (5), pp. 337-340.

Shrout, P.E., \& Fleiss, J.L., 1979. Intraclass correlations: Uses in assessing rater reliability. Psychological Bulletin, 86 (2), pp. 420-428.

Norušis, M.J., 2012. IBM SPSS Statistics 19 Statistical Procedures Companion. Prentice Hall, New Jersey, pp. 456-460.

Che, T., Li, X., Jin, R., Armstrong, R., \& Zhang, T., 2008. Snow depth derived from passive microwave remote-sensing data in China, Annals of Glaciology, 49, pp. 145-154. 